\title{
Motivation and Research Concept of University Library Embedded Service
}

\author{
Guishan Zhang ${ }^{1, \text { a }}$ \\ ${ }^{1}$ Jilin Agricultural University, Changchun, Jilin, 130118 \\ a email
}

Keywords: University Library, Embedded, Motivation, Research Trends

\begin{abstract}
Currently, the emphasis on user-centric embedded user environment to provide personalized design and organization of resources and services for embedded service subject of growing concern. Back in the nineties librarians should be made out of the library, and actively integrate into the user environment, evaluation of user needs, and to provide users with information services, which can be seen as the first interpretation of "embedded services". In 2010, the annual report of the ARL study new positioning in the new environment subject librarians, subject librarian presented should be embedded in user research, teaching and learning process, the establishment of a new model of academic behavior of participating users. Embedded Services proposed to subject librarians at home and abroad to provide a new direction. The past two years, national libraries started to pay attention and study "Embedded service discipline." Embedded discipline services are user-centric, organic integration into the user space physical or virtual space for users to build a personalized information adapted to their needs as the goal of information security environment, mainly in the disciplines provide intensive in-depth information service units, as well as as a basis for restructuring, organizational resources, service design, system architecture, etc. the new operational mechanism. "the researchers believe that service is an extension of embedded service discipline, breaking the limitations of time and space, library services into user-disciplinary research, learning, work, social, networking, mobile and other environments, actively participate in user research study, the full realization of the service to find the user, so the user to extend library services close at hand, and truly become an auxiliary component research study. " Some researchers have proposed embedded disciplines include "Target embedding function embedding, embedding process, embedded systems, embedded in time and space, the ability to embed, embedding emotion, collaborative embedded" in eight aspects.
\end{abstract}

\section{Introduction}

Universities embedded service is subject Subject Librarian University Library and collaborative use of multi-level, multi-faceted resource and strength, discipline services into the user's teaching, research, at the user's physical and virtual spaces to build a user personalized information to meet demand for information security environment. Embedded Library and discipline service overall coordination of all forces, implementation of interactive communication systems engineering co. The ultimate goal of discipline embedded service is an extension of physical and virtual space for library services, enhance visibility and cohesion of services, by way of embedded between personalized user demand and high-quality information and build a more efficient knowledge transfer channel, full support for teaching and research universities to promote academic progress. Embedded Service Discipline Discipline is the new direction of service development at home and abroad there is no uniform standard of service mode, each school libraries can vary due to library system should be designed for teachers and school discipline embedded service mode.

University Library, the most notable is the user's information environment has changed, more and more electronic resources are online, on campus, at home, in the field can be carried by fashion electronic devices via digital remote access to system resources, convenient access to resources, and to the number of physical library less and less. Nothing is there on the Internet, ubiquitous information environment, the user needs and behaviors has also undergone a significant change, 
information ubiquitous technology enables users to be more eager to tap into valuable knowledge and not too much interference information, experience problems when the desire to receive timely and effective professional help, rather than delay guidance lagged skin. University Libraries should fully recognize the seriousness of the crisis in their own survival and development environment, and actively take measures to meet the challenges, speed up transformation of library organizational models and service models. Pan in the library environment, university library services need to deepen the subject for embedded service discipline, subject librarian needs to be embedded into user groups embedded subject librarian. Embedded disciplinary services will enable the library service out of the library building into the user's daily learning, working and living environment, to break the constraints of time and space to become available to the user at hand instant service. Embedded discipline to carry out the Discipline Librarian service in the user relevance, visibility and influence, become an integral part of teaching and research, and to improve and strengthen the interaction with the user, so that subject librarian intermediary role change from becoming partners, teachers and students.

\section{Embedded Services Object Study}

University Library services mainly include researchers, teachers, administrators, policy makers, students and staff. Due to limited resources and staff of the University Library, embedded service discipline can not cover all groups meet the individual needs of all groups, therefore, should be focused on the embedded subject service for different needs of different levels of users. Researchers and teachers is the key service groups, should focus on providing security-service; decision-makers should focus on providing proactive services; students and school staff radiation serve the people, it should focus on providing services heuristics. When embedded discipline service has not understood and recognized by the majority of users, subject librarian should be clever to find a breakthrough in the form of a pilot carried out step by step, after obtaining user acceptance and trust, through appropriate marketing and word of mouth publicity, gradually expand the scope of community service. And this pilot college or professional need to select individual libraries integrate the school disciplines and specialties specific school situation. Only embedded information literacy education for example, Shenyang Normal University Library is selected by the International Business School as a teacher's course starts "ice-breaking journey" because of such embedded foreign teacher in the teaching mode is very familiar with, so they are very active libraries with embedded teaching each year. Inner Mongolia University Library "timely" for the ongoing World Expo application, additional master's degree, college level subjects reporting such conduct embedded teaching. Shanghai Jiaotong University Library, which is a selective advantage discipline and professional conduct of embedded teaching Cheung Kong Scholars national teachers teaching any courses, played "icing on the cake" role.

After determining the service object, subject librarians need to understand the information needs of users looking for embedding Disciplines services and meeting point, and summarizes the common characteristics of regular user groups, user groups, separate the layers, targeted to provide actionable , suitable for an embedded service discipline. First Subject Librarians to analyze and grasp some basic information about cases related disciplines, including teaching system, curriculum, classroom teachers, students and so; and dynamic research projects, research manager, graduate students, discipline construction disciplines, and other developments information. For users personalized information needs of research method can be used, including interviews, questionnaires, research methods conference, telephone survey, a tour of investigation, experiments, etc., or to conduct research including e-mail, an electronic questionnaire by the method of network real-time chat research, log analysis, client user behavior data collection analysis. In practice, interviews and questionnaires are the most commonly used method, often used in combination, while meeting and e-mail questionnaire survey is also more commonly used. Either way, subject librarian should be good at capturing and integrating fragmented information, and promptly organize, analyze and refine. In the Subject Librarians provide users with an embedded service discipline process, through cooperation and interaction with the user, but also constantly monitor 
the dynamic information and knowledge needs of users, and make timely judgments, and for the needs of users, providing the most suitable treatment options, according to a timely subject characteristics of users to integrate a variety of resources and services, to create a truly personalized service discipline environment.

\section{Embedded Disciplinary Services Research Trends}

Embedded library services often face the need to direct users to understand and meet the real needs of users, find and stimulate the potential needs of users, therefore, the embedded library services depends largely on the effective implementation of embedded librarians personal qualities and abilities. How to provide discipline embedded services subject librarian has a corresponding quality and ability, high sense of service, a wealth of academic knowledge, how to learn and improve their comprehensive ability of the system to ensure and strengthen the subject librarian for life, how subject Librarians provide continuing education opportunities to help them promptly charged, to update their knowledge structure to better meet the information needs of users of different disciplines, disciplines embedded security services effectively, the future focus of further research one.

Development and implementation of information technology disciplines embedded services are inseparable. Currently, many libraries are based Web2. 0 development of open source software to build a service platform, which provides users with a one-stop personalized services and internet. In addition, some universities use cloud computing, open source software, network tools and discovery systems Primo, Summon, EDS and other resources to carry out a one-stop search and acquisition, build research information service platform to meet the individual needs of different users. Subject Librarians future will be more need to use the data platform to provide users with tools or services, it is necessary to strengthen research and development, and constantly improve the service functions, so as to effectively overcome the shortcomings and deficiencies of the prior art, erected versatile technology platform, effective implementation services.

Embedded library service is a service to carry out collaborative embedded between librarians and users, to meet the needs of users is the goal and purpose of our service, good cooperation mechanism is the basis for the smooth development of embedded services. Library to change its role from the traditional service provider for the research and teaching essential academic partners, to establish a close cooperative relationship with users through positive interaction with the user, this cooperation includes not only school cooperation, but also include College of Room and cooperation between universities and research institutions disciplinary services.

Embedded discipline service can not be merely superficial, shallow information and knowledge services, the university libraries can be combined with their own school situation, museum situation, in-depth analysis of user needs, active participation, user-friendly design embedded service model, the service ELT run through and permeate all levels to effectively meet the different levels of different types of user's individual requirements.

\section{Conclusion}

Embedded discipline to carry out the service, to provide users with independent, efficient and personalized services to greatly enhance the overall level of the Library Information Service and quality is an important issue facing the modern library. In recent years, embedded disciplines and services around the sharp increase in paper, research paper published in the Journal of Library and Information Science, a higher level and quality of research papers focused on the theme of multi-disciplinary services and embedded service discipline theories, models, approaches and Research issues and trends exist. However, from the overall perspective of the development of embedded disciplinary inquiry service still in the exploratory stage, the difference in various regions of University Services Research and practice of discipline for embedded large subject librarian such as quality of their own presence in advance and carried out in service and work needs to be improved, performance appraisal implementation and improvement services technology issues. 
With the constant improvement of important issues subject librarian system, extensive embedded disciplinary services, related disciplines and services subject librarian embedded information

literacy, technology development, user information needs and specifications of embedded systems and services and other disciplines We will continue to make significant progress.

\section{References}

[1] Chu Jingli. embedded theory library service break [J]. Journal of Academic Libraries, 2013, (6): 5-9.

[2] Liu Ying. University Library Service of the embedded subject [D]. Wuhan University, 2010.

[3] Zhou Xiaojie, Zhang Yang. Chinese Library Embedded Services Review [J]. Library Science, 2012, (12); Liu Xin: 19-22...

[4] Chen Peng. Foreign Embedded Library Services Progress [J]. Library and Information Service, 2013, (3): 5-9. 